\title{
Ultrastructural characteristics of spasm in intracerebral arterioles
}

\author{
WOLFGANG ROGGENDORF, JORGE CERVÓS-NAVARRO \\ From the Institut für Neuropathologie, Klinikum Steglitz der Freien Universität Berlin (West)
}

\begin{abstract}
SUMMARY Following craniotomy, three groups of cats were subjected to three different stimuli: group A hyperventilation, group B electroshock, and group C direct electric current. During electric stimuli, pial vessels were observed through a cranial window. Immediately after electric current application, some arterial vessels showed segmental spastic constriction. Tissue samples for electronmicroscopy were taken from the parietal lobe and nucleus caudatus. In all three groups of animals, different types of constriction of blood vessels were observed. The respiratory alkalosis achieved by hyperventilation led to physiological constriction of the arterioles. The electric stimuli led to spastic constriction of the meningeal and intracerebral arteries and arterioles in group B and C; the entire vessel wall was greatly deformed and the vessel lumen was almost obstructed. Electroshock resulted in only moderate structural changes of the smooth muscle cells. Direct current, however, caused an extreme and bizarre smooth muscle deformation. The results show that spastic constrictions of arterioles can be clearly distinguished from physiological, that is non-spastic constriction, by morphological parameters. Electric stimulation of cerebral vessels could be an experimental condition for further investigation of intracerebral vasospasm.
\end{abstract}

Spastic constriction occurs in larger intracranial arteries and may influence cerebral circulation, especially after aneurysmal rupture followed by subarachnoid haemorrhage, as shown by clinical and experimental investigations by Echlin, Wilkens et al, and Peterson et al.1-3 Ultrastructural studies by Matakas et $a l^{4}$ and Cervós-Navarro et al ${ }^{5}$ have revealed spastic constrictions also in intracerebral arterioles under various experimental conditions. The purposes of this investigation were (1) definition of morphological criteria for identification of contraction of smooth muscle cells in blood vessel walls under physiological conditions, and (2) to determine whether spastic contraction produced by various electrical stimuli was accompanied by specific morphological changes.

\section{Material and methods}

For this study we used 21 adult cats $(2-3 \mathrm{~kg})$, which were anaesthetised with intramuscular sodium pentobarbital (Nembutal $25 \mathrm{mg} / \mathrm{kg} \mathrm{bw}$ ). A catheter was inserted into the

Address for reprint requests: Professor J Cervós-Navarro, Universitäts Klinicum Steglitz, Hindenburgdamm 30, D 1000 Berlin 45, W. Germany.

Received 27 May 1981 and in revised form 7 September 1981 Accepted 26 September 1981 aorta and into the inferior vena cava through the femoral artery and vein, respectively. Arterial blood pressure was monitored and remained at normal levels throughout the experiments. After relaxation with succinyl-bis-choline ( $2 \mathrm{mg})$ and intubation, the animals were artificially ventilated. Blood gases were kept normal (arterial pressure of $\mathrm{CO}_{2} 35-45 \mathrm{~mm} \mathrm{Hg}, \mathrm{pH} 7 \cdot 35$, arterial pressure of $\mathrm{O}_{2}$ 90-110 $\mathrm{mm} \mathrm{Hg}$ ).

The cats were divided into 3 groups:

Group $A$ Respiratory alkalosis in nine cats was achieved by hyperventilation for $20 \mathrm{~min}(82 \mathrm{ml}$, frequency $28-33 / \mathrm{min}$ ) (Cervós-Navarro et $a l^{6}$ ).

Group $B$ Electroconvulsive treatment was applied in six cats after craniotomy. Two metal electrodes, each with a diameter of $10 \mathrm{~mm}$, were attached to the temporal muscle on each side. An alternating current of $220 \mathrm{~V} 50 \mathrm{~Hz}$ was applied for $500 \mathrm{~ms}$ at a time, two to five times within 5 minutes. After 20 minutes, the animals were killed by injecting $50 \mathrm{ml}$ of India ink suspension within $10 \mathrm{~s}$ into the inferior vena cava.

Group C For electric stimulation by direct current (DC) in six cats after craniotomy, one electrode (10 $\mathrm{mm}$ diameter) was attached to the right temporal muscle. The left electrode was an Agar-gel silver electrode with a plastic tube of inner tip diameter of about $0.20 \mathrm{~mm}$. DC with $20-100 \mathrm{~V}$ for 2 to $30 \mathrm{~s}(20-150 \mathrm{ma})$ was applied. In two animals, two assessments were made. In four animals, three were made. 
In group $\mathrm{B}$ and $\mathrm{C}$, the animals were killed $20 \mathrm{~min}$ after electrical stimulation by injecting $50 \mathrm{ml}$ of India ink suspension rapidly into the inferior vena cava.

A control group of 12 cats was used. Six of these cats were only normally ventilated. The remaining six cats were treated as group B and C, but the cerebral vessels were not subjected to electric stimulation. After treatment of 20 min (group A) or immediately after injection of India ink (group B and C), $5 \mathrm{~mm}^{3}$ blocks of parietal cortex and subcortical white matter and of the caudate nucleus were excised quickly for electron-microscopy. The brain was then removed and fixed in formalin. The tissue for electronmicroscopy was fixed for 2 hours in chilled $5 \%$ buffered glutaraldehyde, washed in buffered saccharose solution, postfixed in $1.0 \%$ osmium tetroxide, dehydrated and embedded in epon. The brain specimens in this study were fixed by immersion in order to prevent reduction of the spasm which might occur with fixation by perfusion under pressure. Immersion fixation was also necessary for the groups of experimental animals which were perfused with India ink in order to observe the no reflow phenomenon and the spastic constriction of arterioles along large segments.

The control brains of regularly ventilated cats were also fixed by immersion. Arterioles in these brains showed only a slight contraction evidenced by undulation of the basal lamina. Marked constriction or even spasm of arterioles was not observed in any of the control brains. There were no differences between normal cat brain arterioles fixed by immersion or by perfusion with regard to the appearance of the cellular organelles. In particular pinocytotic activity and filamentous components in endothelial cells were identical.

The gross and microscopic aspects of groups B and C after India ink injection have been described in detail by Matakas $e t a^{4}$ (we will give only a short summary). In some cortical areas, patches without blackening of India ink were observed, indicating that cerebral circulation was disturbed. In all cases, light-microscopically large arterioles and arteries varied in diameter and showed some segments completely spastic. The spastic segments were exclusively observed in the grey substance of the brain and in either the cortex or basal ganglia.

In the following description, we refer to spastic contraction when marked deformation of the entire vessel wall leads to a completely obstructed vessel in contrast to physiological contraction produced by alkalosis, in which the basic configuration of the vessel is retained.

\section{Results}

1 ENDOTHELIUM AND SUBENDOTHELIAL SPACE

In groups $\mathrm{A}, \mathrm{B}$, and $\mathrm{C}$, oval to round endothelial cell nuclei covered by a thin rim of cytoplasm protruded far into the vessel lumen (fig 1). In the endothelial cell body away from the nuclear zone, slender, digital cytoplasmic extensions projected towards the vessel lumen (figs 1, 2).

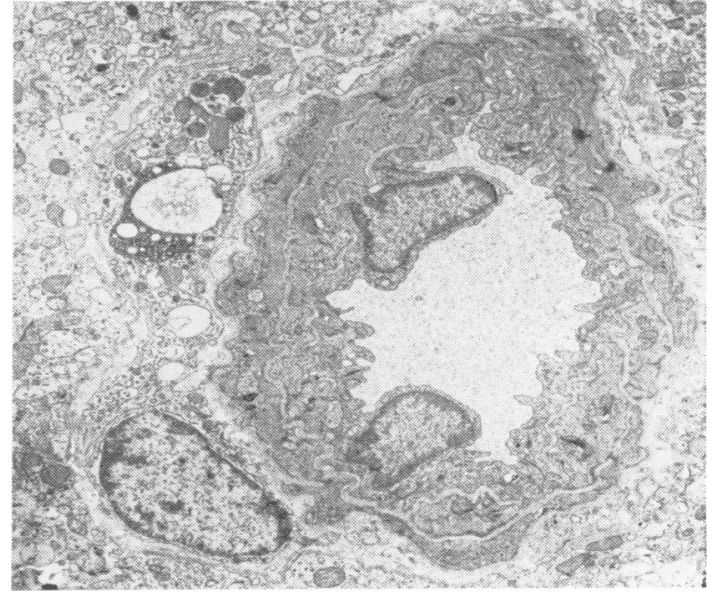

Fig 1 Arteriole from the cortex in physiological contraction (group A) with finger-like narrow protrusions of endothelium and strongly scalloped subendothelial space. Fixation by immersion. $\times 2880$.

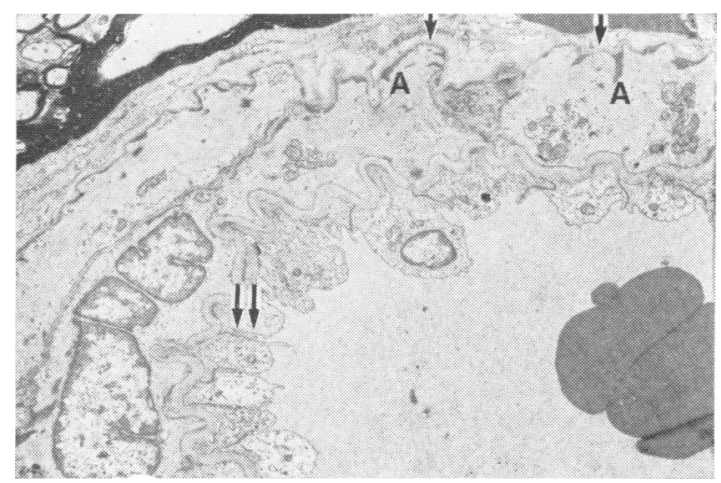

Fig 2 Contracted arteriole from the nucleus caudatus (group A) with the characteristic deformation of the smooth muscle cells: between attachment devices $(A)$, the cell membrane bulges out $\rightarrow$ ). The endothelial tight junctions are set upright $(\rightarrow)$. Fixation by immersion. $\times 7160$.

Slightly increased endothelial pinocytosis was evident only in the first experimental group (physiological constriction after respiratory alkalosis). In both of the experimental groups of animals exposed to electric stimulation, no changes in endothelial pinocytotic activity were observed, possibly because of the short duration on the experiments. The endothelial tight junctions in dilated vessels ran diagonally and overlapped. In contracted arterioles (group A), the junctions usually ran perpendicular to the basal membrane (fig 2). Spicular cytoplasmic extensions containing clusters of $7 \mathrm{~nm}$ filaments were also seen, arising abluminally from the endothelial cells of 


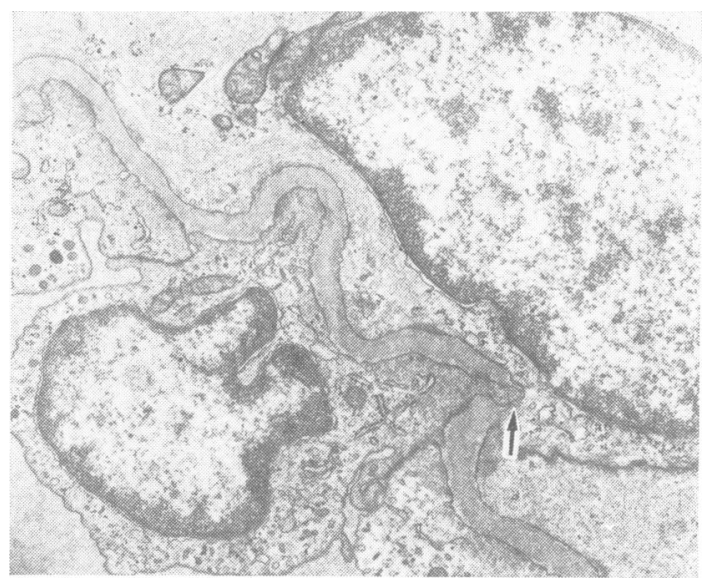

Fig 3 Microfilaments of the endothelium are especially close to the basal lamina and increase near myoendothelial junctions $(\rightarrow)($ group $A)$. Fixation by immersion. $\times 10285$.

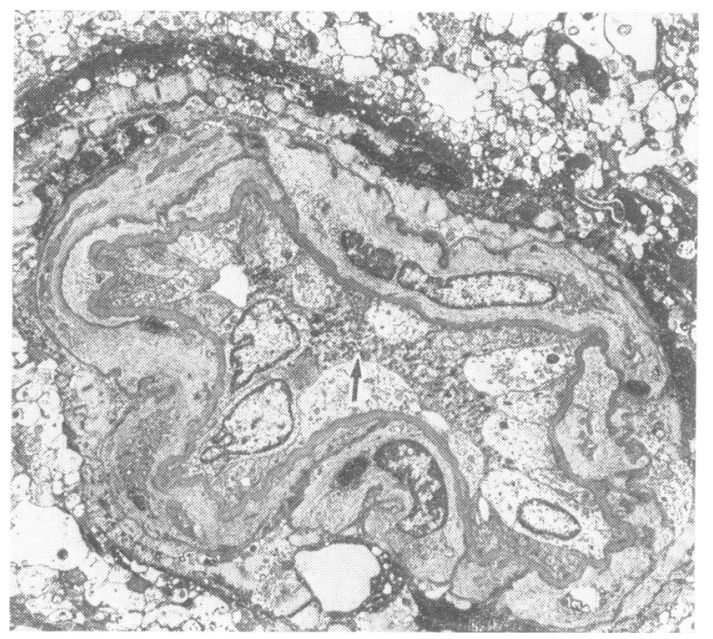

Fig 4 Spastic arteriole of the cortex (group B): cleftlike vessel lumen with particles of India ink $(\rightarrow)$. Widened perivascular space. India ink perfusion. Fixation by immersion. $\times 2640$.

contracted arterioles (fig 3). The basal lamina was widened. In the arterioles strongly or spastically contracted by electroshock and direct current (group B, C), the basal membrane appeared more homogeneous and less electron-dense than in noncontracted or simply contracted arterioles (figs 2,5 ). A detailed description of the media and of the perivascular space will be given separately.

\section{MEDIA}

The media differed conspicuously in the three different groups. The muscle cells of a 1-2-layer media of intracerebral arterioles of cats of group $A$ which showed simple contraction were characterised by: moderate deformation of the smooth muscle cell, with compression and indentation of the nucleus, the cell membrane was extremely scalloped and showed deformation of the prominent attachment devices, their broad bases were situated in the cell membrane and extended into the cell like a supporting belt. The cytoplasm with the pinocytotic vesicles lined up along the cell membrane bulged out between the attachment devices towards the abluminal side (figs $2,7)$. Here the diameter of the media wall remained almost constant. Moreover, spastically contracted arterioles occurred occasionally with an almost completely obstructed vessel lumen. In animals of group A we occasionally found obstructed blood vessels in which deformation of endothelium, subendothelial space and smooth muscle cells followed the pattern defined above as spastic contraction. In arterioles of group $B$, the lumen was almost completely occluded while endothelial cells, subendothelial space and smooth muscle cells were only slightly scalloped. The nucleus of the smooth muscle cell appeared moderately scalloped. The abluminal membrane of smooth muscle cells was flattened in large segments. The triangular attachment devices were situated on the cell membrane without leading to the deformation characteristic of simple contraction. Occasionally there was a narrow patch of

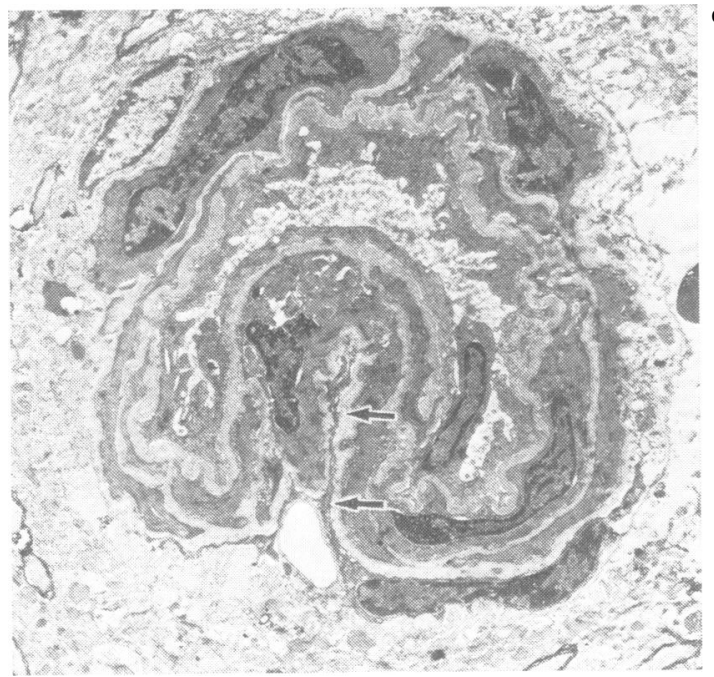

Fig 5 Arteriole (group $C$ ): widened subendothelial space. Indentation of the whole vessel wall with a small process of an adventitial cell $(\rightarrow)$. Dark cytoplasm of smooth muscle cells. India ink perfusion. Fixation by immersion. $\times 2615$. 
electron-dense marginal border, which was possibly formed by contiguous attachment devices (figs 4, 6a). Next to spastically contracted vessel sections with completely occluded lumina, one also found sections, where the vessel wall was only moderately infolded. The endothelium was flattened, the subendothelial space appeared only moderately undulated, and the media showed very slight deformation. The width of the vessel wall was nearly constant. The interconnection of the muscle cells by myomyal tight junctions did not differ from those in physiological contraction.

The spastically contracted arterioles from cats of

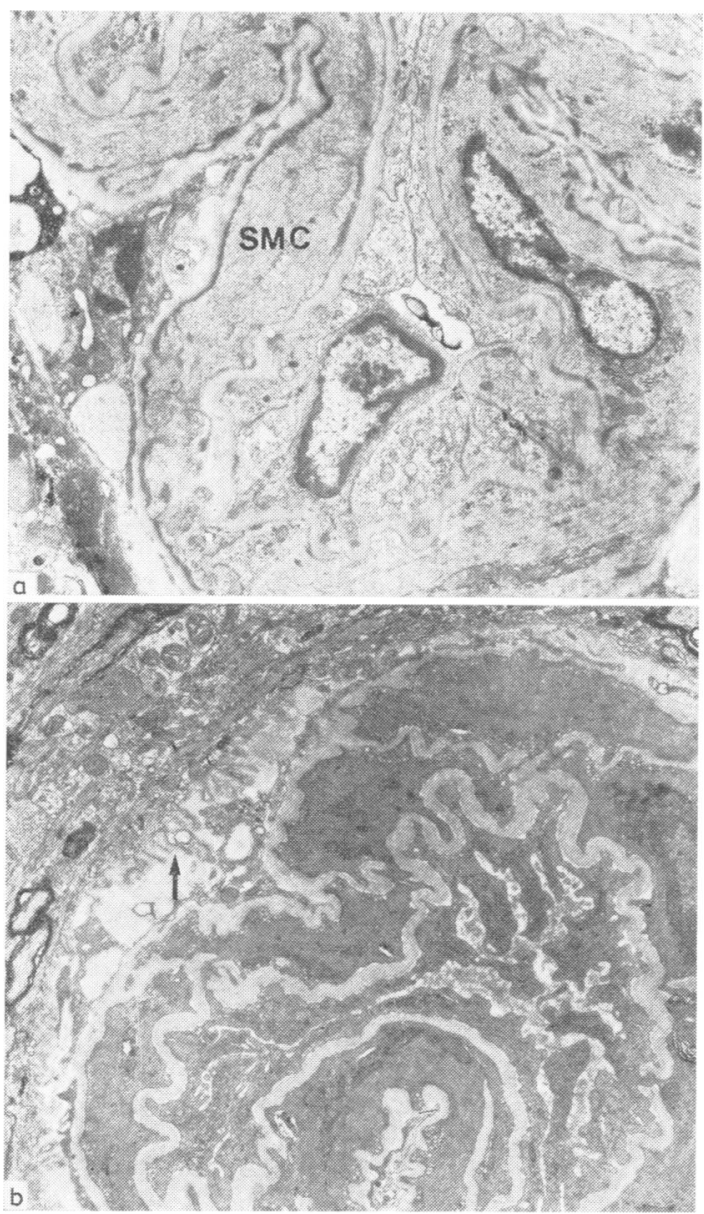

Fig 6(a) Arteriole (group B). The smooth muscle cells (SMC) show no strong deformation of the cell membrane as opposed to (b).

(b) The arteriole of group $C$, which shows a bizarre deformation of smooth muscle cells and endothelium. Small processes of glia in the perivascular space $(\rightarrow)$. (a) $\times 6360$ (b) $\times 5830$.

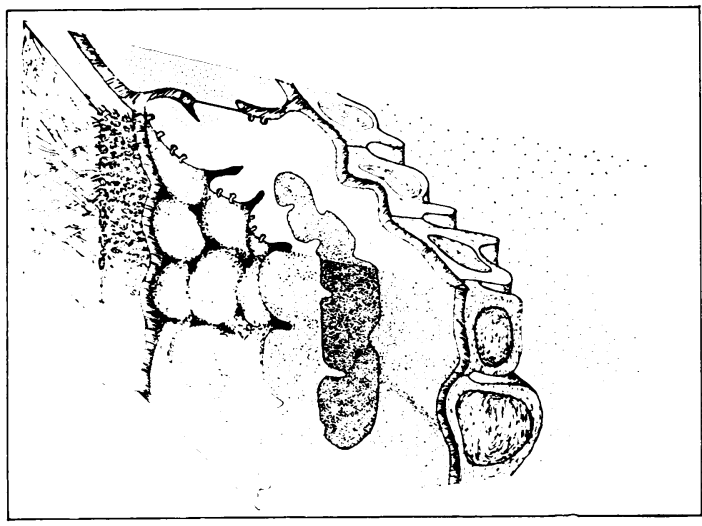

Fig 7 Schematic presentation of the physiological constriction mechanism: the cell membrane was extremely scalloped and showed deformation by attachment devices, which work as a cytoskeleton during constriction.

group $C$ showed a bizarre, extreme deformation of the muscle cell (fig 5). The usual regular distance of 0.15 to $0.20 \mu \mathrm{m}$ between muscle cells became irregular, sometimes twice as wide. Occasionally there were gap zones in which the basal membrane of subendothelial space appeared contiguous with the glial basal membrane. The muscle cells were very narrow and formed narrow spicular cell processes, both luminally and abluminally. There was no deformation of the abluminal cell membrane by attachment devices. Myomyal tight junctions were rare and limited to narrow muscle cell processes (fig 6b).

\section{Perivascular SPACE}

The perivascular space in all three groups of cats appeared as a gap that only occasionally showed a dilatation. It contained uniformly narrow adventitial cell branches, nerves, and collagen fibres. In contrast to uncontracted arterioles and arterioles of groups A and B, narrow folds occurred in the glial and its basal membrane in the spastically contracted arteriole of group C (figs 5, 6b). Occasionally attenuated glial processes (fig $6 \mathrm{~b}$ ) protruded into the perivascular space.

\section{Discussion}

Our observations on the intracerebral arterioles show a characteristic group of morphologic changes accompanying physiological contraction. In the endothelial cells, clusters of filaments were seen in the abluminal cytoplasm near tight junctions. The basal lamina was undulated, and smooth muscle cells were 
deformed by a scalloped cell membrane and prominent attachment devices. The vessel diameter was markedly decreased. However, the vessel lumen was not obstructed. These findings are in agreement with the observations by light microscopy on small arterioles undergoing physiological contraction ${ }^{7}$ and with the ultrastructural findings in mesenteric arterioles by Phelps and Luft. ${ }^{8}$ In particular the presence of contractile filaments within the endothelial cells observed by us and others ${ }^{9-11}$ indicates that the endothelium plays an active role in the contractile process. Further, these contractile filaments may determine the typical arrangement in endothelial cells.

The spastic constrictions of arterioles can be clearly distinguished from the physiological, that is non-spastic constriction by morphological parameters. Both DC and electroshock lead to a spastic constriction with occlusion of the vessel lumen. There is no characteristic deformation of smooth muscle cell membrane by attachment devices and no typical undulation of the basal lamina. The perivascular glia participates in the spasm by folding of the astrocytic plasma membrane and the glial basal lamina probably because of a reduction of the total surface of the glial ensheathment.

These morphological changes indicate that it is possible to produce a complete obstruction of the vessel lumen with both electric stimulation methods, DC and electroshock. The effect of these electrical stimuli on the microcirculation is described in more detail by Matakas et al ${ }^{4}$ and Cervós-Navarro et al. ${ }^{5}$

Morphologic alterations occurring with spastic processes are not homogeneous. There are morphologic differences between the spastic vessels in group $\mathbf{B}$ and group $\mathbf{C}$. The principal difference involves the reaction of the smooth muscle cell. In cases where the spasm has been induced by direct current (group C), the spastic constriction is characterised by a bizarre deformation of smooth muscle cells. In cases where spasm was produced by electroshock (group B) there is only a moderately scalloped smooth muscle cell layer and no deformation of the smooth muscle cell membrane by attachment devices. We believe that a spastic contraction is not an extreme deformation of the single muscle cell but rather a folding and indentation of the whole vessel wall which leads to occlusion of the lumen.

The question arises as to whether spastic contraction takes place without typical signs of the physiological constriction. We consider that the pattern of contraction depends on the arrangement of the smooth muscle cells of the media. The spiral pattern of the smooth muscle cells found in small arteries and arterioles by Benninghoff ${ }^{12}$ by light microscopy has been confirmed by ultrastructural examinations. Roggendorf and Cervós-Navarro ${ }^{13}$ showed non-contracted intracerebral arterioles with a nearly circular course with interruptions in the smooth muscle cell layer by segments in which the myofilaments of neighbouring smooth muscle cells are arranged vertically on top of one another in the course of a two layered media. In tangential sections, Rhodin ${ }^{14}$ demonstrated that the muscle cells of the outermost layer are spirally arranged in a pitch of $18^{\circ}$. This spiral course of the smooth muscle cell renders possible the extreme deformation and deep indentation of the vessel in the presence of spastic contraction with occlusion of the vessel lumen. Lesions of single cells, for example in the endothelium or in the smooth muscle cells were not found more often in experimental animals than in the control animals. There were no significant changes of organelles, generalised vacuolisation or oedema. These observations are in agreement with the studies of Fein $e t a l^{15}$ and Tanabe $e t a l,{ }^{16}$ which revealed that there are no changes due to spasm in the first hour after stimulation. The intriguing phenomenon of the segmental arrangement of spasm, which is well documented in meningeal vessels after subarachnoidal haemorrhage 21718 cannot be explained by the results of our electron microscopical study. A systematic investigation of the precise mechanism of intracerebral spasm, however, could be based, at least in part, on experimental conditions derived from this investigation with electric stimulation of intracerebral arteries and arterioles.

\section{References}

${ }^{1}$ Echlin FA. Spasm of the basilar and vertebral arteries caused by experimental subarachnoid hemorrhage. $J$ Neurosurg 1965;23:1-11.

${ }^{2}$ Wilkins RH, Alexander JA, Odom GL. Intracranial arterial spasm: a clinical analysis. J Neurosurg 1968; 29:121-34.

${ }^{3}$ Peterson EW, Searle R, Mandy FF et al. The reversal of experimental vasospasm by dinutyryl-3'-adenosine monophosphate. J Neurosurg 1973;39:730-4.

${ }^{4}$ Matakas F, Cervós-Navarro J, Roggendorf W et al. Spastic constriction of cerebral vessels after electric convulsive treatment. Fortschr Psychiatr Nervenhlk 1977;224:1-9.

${ }^{5}$ Cervós-Navarro J, Matakas F, Roggendorf W et al. The morphology of spastic intracerebral arterioles. Neuropath and Neurobiol 1978;4:369-79.

${ }^{6}$ Cervós-Navarro J, Leipert M, Valencak E et al. La morphologie ultrastructurale du S.N. dans "la perfusion de luxe" de l'acidose respiratoire. Neurochirurgie 1971;17:595-600.

${ }^{7}$ Citters RL van, Wagern BM, Rushmer RF. Architecture of small arteries during vasoconstriction. Circ Res 1962;10:668-75.

${ }^{8}$ Phelps PC, Luft JH. Electron microscopical study of 
relaxation and constriction in frog arterioles. $A m J$ Anat 1969;125:399-429.

${ }^{9}$ Becker CG, Murphy GE. Demonstration of contractile protein in endothelium and cells of the heart valves, endocardium, intimal arteriosclerotic plaques, and Aschoff bodies of rheumatic heart disease. Am J Path $1969 ; 55: 1-37$.

${ }^{10}$ Becker CG, Nachman RL. Contractile proteins of endothelial cells, platelets, and smooth muscle. Am J Path 1973;71:1-22.

${ }^{11}$ Owman Ch, Edvinsson L, Hardebo JH et al. Immunochemical demonstration of actin and myosin in brain capillaries. In: Cervós-Navarro J, ed. Advances in Neurology, Vol. 20. New York: Raven Press, 1978: 35-7.

12 Benninghoff A. Blutgefäße und Herz. In: Handbuch der mikroskopischen Anatomie des Menschen. Möllendorf W, ed. Berlin: Springer Verlag, 1930: 134.
${ }^{13}$ Roggendorf W, Cervós-Navarro J. Ultrastructure of arterioles in the cat brain. Cell Tiss Res 1977;178: 495-515.

14 Rhodin JAG. Fine structure of vascular walls in mammals with special reference to smooth muscle component. Physiol Rev 1962;42:48-81.

${ }^{15}$ Fein JM, Flor WJ, Cohan SL et al. Sequential changes of vascular ultrastructure in experimental vasospasm. Myonecrosis of subarachnoid arteries. $J$ Neurosurg 1974;41:49-58.

16 Tanabe Y, Sakata K, Yamada H et al. Cerebral vasospasm and ultrastructural changes in cerebral arterial wall. $J$ Neurosurg 1978;49:229-38.

17 Arutiunow AI, Baron MA, Majorova NA. Experimental and clinical study of the development of spasm of cerebral arteries related to subarachnoid hemorrhage. $J$ Neurosurg 1970;32:617-25.

${ }^{18}$ Lende RA. Local spasm in cerebral arteries. $J$ Neurosurg 1960;17:90-103. 